\title{
Association between Sociodemographic Factors and Sleeping Patterns from Infancy to Four Years of Life in Saudi Community
}

\author{
Gigi Sam*, Sarah Zinaf, Maha Hamoud and Noora Inad \\ College of Pharmacy, Shaqra University, Kingdom of Saudi Arabia \\ *Corresponding author: Gigi Sam, Lecturer, College of Pharmacy, Shaqra University, Kingdom of \\ Saudi Arabia, Tel: 0557169060
}

\begin{abstract}
Objective: Sleep is a prime factor of healthy development and has been associated with emotional, behavioural, and cognitive development. This study investigates sleep parameters and associated sociodemographic characteristics in a population-based online method in Saudi children from infancy to four years of life.

Methods: A Brief Infant Sleep Questionnaire (BISQ) for sleep assessment was made available to participants through the web link in Arabic language and were filled by the mothers. The target population were divided into three age groups: 0-11 months, 1-2 years, and 2-4 years. Questions related to demographic factors and sleep problems like bedtime resistance, sleep anxiety, nocturnal awakenings and daytime sleepiness were included. Data were evaluated by logistic regression analysis $(p \leq 0.05)$ using software $R$.

Results: 1264 individuals participated in the study, which included $51.3 \%$ and $48.7 \%$ of male and female children respectively. Sleep disorders were significantly associated with age of child, mode of birth, mother's occupation, family type, parent's sleep time, sleep onset and sleep duration $(P<0.05)$. Inadequate bedtime habits and sleep duration below the recommended levels were observed in all age groups.

Conclusions: The present study showed the prevalence and association between sleeping patterns and different sleep parameters and could be used to inform future research on how to increase parental knowledge of healthy sleep practices and adequate sleep among young children.
\end{abstract}

\section{Keywords}

Sleep, Sleep patterns, Sleep duration, Child's age

\section{Introduction}

Children, during the entire first decade of their life, spend the majority of time in sleeping which makes it crucial to understand the role of sleep, particularly in early life. Healthy sleep is pivotal for the child's body and brain growth. It is also associated with physical health, memory and socio-emotional development $[1,2]$. Sleep problems has been associated both with current and future symptoms of emotional and behavioural problems, as well as cognitive development $[2,3]$. Children who have shorter sleep duration, insufficient sleep at night, and sleep onset problems have higher odds of social-emotional problems, even if taken into account the developmental problems and demographic factors [4]. Over the years, it may diminish the self-regulation abilities of young children, resulting in higher risk of behavioral and school problems [5].

Quantitative research on young children's sleep has shown that sleep duration is associated with behavioural and cognitive outcomes [6]. Language-based bedtime routines are associated with longer sleep duration and higher verbal scores [7] and longer nighttime sleep duration is associated with larger vocabulary among pre-schoolers [8]. A recent study conducted in the Middle East pictured that the toddlers and their mothers who had a delayed sleep time and very late waking up in the morning had negative effects on mood outcomes. This widespread sleep problems in both toddlers and their mothers suggests the need for sleep to be addressed by medical practitioners

Citation: Sam G, Zinaf S, Hamoud M, Inad N (2020) Association between Sociodemographic Factors and Sleeping Patterns from Infancy to Four Years of Life in Saudi Community. Int J Pediatr Res 6:059. doi. org/10.23937/2469-5769/1510059

Accepted: February 11, 2020: Published: February 13, 2020

Copyright: (C) 2020 Sam G, et al. This is an open-access article distributed under the terms of the Creative Commons Attribution License, which permits unrestricted use, distribution, and reproduction in any medium, provided the original author and source are credited. 
[9]. Children strongly depend on their parents understanding of sleep needs and requirements. However, parents actually have poor knowledge about sleep problems, and this is one of the leading causes for seeking professional help in the early stages of childhood development. Suggesting a need for educating them about the signs of sleep problems and sleep requirements to ensure a healthy sleep regimen is followed $[10,11]$.

The aim of the present study was to report sleep parameters from infancy to four years of life and identify associated sociodemographic factors in a relatively large group of children born in the period of 2015 to 2018 in the Kingdom of Saudi Arabia. We examined a range of sleep parameters like sleep duration, sleep onset, child's sleep time, parent sleep time, siblings sleep time etc., to the sleeping disorders (bedtime resistance, sleep anxiety, nocturnal awakening, daytime sleepiness) which contributed to the predominant development of a child.

\section{Materials and Methods}

\section{Participants}

Mothers of 1264 infants and toddlers from Saudi Arabia participated in this study.

The age of the children ranged from birth to four years evenly distributed across boys (51.3\%) and girls (48.7\%).

\section{Procedure}

All data were collected online. The questionnaire was prepared using google form and completion of the questionnaire was voluntary, there were no exclusionary criteria, and this study was approved by the Institutional Review Board at Shaqra University. The complete sample was collected in January 2019 to February 2019. All participants completed the expanded Brief Infant Sleep Questionnaire (BISQ), and demographic information (e.g., parental age, education, race, and employment status). All questionnaires were translated into Arabic and back-translated to ensure accuracy.

The study included all births which took place from 1 January 2014 to 31 December 2018 in the various region of Saudi Arabia and were divided into three age groups: From 0 to 11 months, 1-2 years and 3-4 years.

The questionnaire consisted of two parts: The first part included demographic information, and the second part comprised 20 questions regarding the sleep patterns and sleep habits of children. This part was divided into 6 subsections: 1) Bedtime resistance; 2) Sleep onset; 3) Sleep duration; 4) Sleep anxiety; 5) Nocturnal wakening; 6) Daytime sleepiness.

\section{Results}

\section{Demographic factors}

Complete demographic data for the sample are provided in Table 1.

Table 1: Demographic characteristics.

\begin{tabular}{|c|c|c|c|}
\hline & \multicolumn{3}{|c|}{ Age Group of Child } \\
\hline & $\begin{array}{l}0-1 \text { year } \\
(N=54)\end{array}$ & $\begin{array}{l}1-2 \text { years } \\
(\mathrm{N}=330)\end{array}$ & $\begin{array}{l}\text { 2-4 years } \\
(\mathrm{N}=880)\end{array}$ \\
\hline \multicolumn{4}{|l|}{ Sex } \\
\hline Male & $30(55.6 \%)$ & $158(47.9 \%)$ & $461(52.4 \%)$ \\
\hline Female & $24(44.4 \%)$ & $172(52.1 \%)$ & $419(47.6 \%)$ \\
\hline \multicolumn{4}{|l|}{ Occupation of Mother: } \\
\hline Employee & $17(31.5 \%)$ & $123(37.3 \%)$ & $361(41.0 \%)$ \\
\hline Housewife & $29(53.7 \%)$ & $168(50.9 \%)$ & $465(52.8 \%)$ \\
\hline Married student & $8(14.8 \%)$ & $39(11.8 \%)$ & $54(06.1 \%)$ \\
\hline \multicolumn{4}{|l|}{ Mode of Delivery: } \\
\hline Caesarean & $11(20.4 \%)$ & $90(27.3 \%)$ & $231(26.3 \%)$ \\
\hline Vaginal & $43(79.6 \%)$ & $240(72.7 \%)$ & $649(73.8 \%)$ \\
\hline \multicolumn{4}{|c|}{ Mother's age at the birth of a child: } \\
\hline $18-29$ years & $37(68.5 \%)$ & $222(67.3 \%)$ & $542(61.6 \%)$ \\
\hline $30-39$ years & $13(24.1 \%)$ & $98(29.7 \%)$ & $278(31.6 \%)$ \\
\hline $40-49$ years & $4(07.4 \%)$ & $10(03.0 \%)$ & $60(06.8 \%)$ \\
\hline \multicolumn{4}{|l|}{ Mother's education level } \\
\hline Middle school & $7(13.0 \%)$ & $30(09.1 \%)$ & $109(12.4 \%)$ \\
\hline High school & $13(24.1 \%)$ & $57(17.3 \%)$ & $207(23.5 \%)$ \\
\hline BA & $34(63.0 \%)$ & $243(73.6 \%)$ & $564(64.1 \%)$ \\
\hline
\end{tabular}




\begin{tabular}{|c|l|l|l|}
\hline Child's siblings & & & \\
\hline He has no brother & $26(48.1 \%)$ & $131(39.7 \%)$ & $145(16.5 \%)$ \\
\hline one brother/sister & $8(14.8 \%)$ & $56(17.0 \%)$ & $211(24.0 \%)$ \\
\hline Two & $3(05.6 \%)$ & $41(12.4 \%)$ & $148(16.8 \%)$ \\
\hline More than two & $17(31.5 \%)$ & $102(30.9 \%)$ & $376(42.7 \%)$ \\
\hline Housing independence & & & \\
\hline Nuclear & $45(83.3 \%)$ & $284(86.1 \%)$ & $710(80.7 \%)$ \\
\hline Extended & $9(16.7 \%)$ & $42(12.7 \%)$ & $139(15.8 \%)$ \\
\hline Joined & $0(00.0 \%)$ & $4(01.2 \%)$ & $31(03.5 \%)$ \\
\hline
\end{tabular}

Table 2: Sleep parameters vs. age group of the child.

\begin{tabular}{|c|c|c|c|}
\hline & $\begin{array}{l}0-1 \text { year } \\
(N=54)\end{array}$ & $\begin{array}{l}1-2 \text { years } \\
(N=330)\end{array}$ & $\begin{array}{l}2-4 \text { years } \\
(N=880)\end{array}$ \\
\hline \multicolumn{4}{|l|}{ Sleep onset } \\
\hline Within 20 minutes & $30(55.6 \%)$ & $184(55.8 \%)$ & $390(44.3 \%)$ \\
\hline More than 20 minutes & $24(44.4 \%)$ & $146(44.2 \%)$ & $490(55.7 \%)$ \\
\hline \multicolumn{4}{|l|}{ Child's sleep duration } \\
\hline Less than 10 hours & $29(53.7 \%)$ & $128(38.8 \%)$ & $323(36.7 \%)$ \\
\hline $10-12$ hours & $18(33.3 \%)$ & $159(48.2 \%)$ & $479(54.4 \%)$ \\
\hline $12-14$ hours & $3(05.6 \%)$ & $37(11.2 \%)$ & $71(08.1 \%)$ \\
\hline More than 14 hours & $4(07.4 \%)$ & $6(01.8 \%)$ & $7(00.8 \%)$ \\
\hline \multicolumn{4}{|l|}{ Child's sleep time } \\
\hline $8: 00 \mathrm{pm}$ & $17(31.5 \%)$ & $55(16.7 \%)$ & $112(12.7 \%)$ \\
\hline at 10 or $11 \mathrm{pm}$ & $27(50.0 \%)$ & $173(52.4 \%)$ & $506(57.5 \%)$ \\
\hline at 12 or later & $10(18.5 \%)$ & $102(30.9 \%)$ & $262(29.8 \%)$ \\
\hline \multicolumn{4}{|l|}{ Parent's sleep time } \\
\hline $8: 00 \mathrm{pm}$ & $5(09.3 \%)$ & $3(00.9 \%)$ & $14(01.6 \%)$ \\
\hline at 10 or $11 \mathrm{pm}$ & $21(38.9 \%)$ & $113(34.2 \%)$ & $310(35.2 \%)$ \\
\hline at 12 or later & $28(51.9 \%)$ & $214(64.8 \%)$ & $556(63.2 \%)$ \\
\hline \multicolumn{4}{|l|}{ Sibling's sleep time } \\
\hline $8: 00$ pm & $10(18.5 \%)$ & $58(17.6 \%)$ & $123(14.0 \%)$ \\
\hline at 10 or $11 \mathrm{pm}$ & $33(61.1 \%)$ & $179(54.2 \%)$ & $520(59.1 \%)$ \\
\hline at 12 or later & $11(20.4 \%)$ & $93(28.2 \%)$ & $237(26.9 \%)$ \\
\hline
\end{tabular}

A total of 1264 individuals participated in the study. Of these, 54 were in the $0-11$ months age group (30 males, 24 females), 330 in the $1-2$ years age group (158 males, 172 females), and 880 in the 3-4 years age group (461 males, 419 females). Sex distribution was homogeneous among the three age groups $(51.3 \%$ males and $48.7 \%$ females).

The majority of mothers (65.8\%) were between 18 and 29 years old, most had a college degree (67\%), and the majority were not employed outside the home (52.5\%). Nearly $82.2 \%$ of children lived in independent family.

\section{Sleep parameters vs. age group of the child}

According to the revised recommended sleep duration as specified in the national sleep foundation, child of an age of 11 months should sleep for 12 to $15 \mathrm{hrs} /$ day, while 1-2 years with a range of $11-14$ hrs/day and 3-5 years with 10-13 hrs/day [12]. But in the study conducted, it was found that $53.7 \%$ of 0 to 11 months, $38.8 \%$ of $1-2$ years and $36.7 \%$ of $3-4$ years slept less than $10 \mathrm{hrs} /$ day. In all age groups, the frequency of sleep duration was comparatively less than the values recommended by the National Sleep Foundation. On an average, $56 \%$ of children went to bed after $10 \mathrm{pm}$ and $30 \%$ at about 12 am in the morning. The sleep onset was observed to be greater than 20 minutes for $52 \%$ of children. The parent's and sibling's sleep time too had a greater impact on the sleep time of the child which eventually reduced the sleeping duration which is very essential for the physical, mental and social development of the child (Table 2).

\section{Comparison of sleeping pattern with different vari- ables}

Sleep onset: Sleep onset of the child has a significant 
effect with the bedtime resistance (avg $=23.1, \mathrm{SD}=7.7$, $p=0.025)$, sleep anxiety ( $\operatorname{avg}=17.2, S D=7.6, p<0.001$ ) and nocturnal wakening (avg $=12.8, S D=6.2, p=0.015$ ).

Sleep duration: Sleep duration influences sleep anxiety (avg $=16.7, S D=7.8, p<0.001)$ and daytime sleepiness (avg $=21.4, S D=6.5, p=0.036$ ).

Sleep time of the child is associated with bedtime resistance (avg $=23.1, \mathrm{SD}=7.7, \mathrm{p}=0.039$ ) whereas the sleep time of the parent also has an influence over the nocturnal wakening of the child (avg $=12.8, S D=6.1, p$ $=0.003$ ) and daytime sleepiness of the child (avg $=21.1$, $S D=6.6, p=0.009$ ).

Age of child and mode of birth: A very interesting fact noted was that the mode of child birth was associated with daytime sleepiness (avg $=20.9, \mathrm{SD}=6.7, \mathrm{p}$ $=0.045)$ and also the children of working mother had been associated with sleep anxiety ( $\operatorname{avg}=17.2, \mathrm{SD}=7.7$, $\mathrm{p}<0.001$ ) and daytime sleepiness (avg $=21.0, \mathrm{SD}=6.6$, $p=0.019)$. Nocturnal wakening of the child was more frequently influenced by the type of family (avg $=13.3$, $S D=6.3, p=0.025$ ). It was found that age of children had a significant effect with sleep anxiety (avg $=17.0$, $S D=7.4, p=0.006)$, nocturnal wakening (avg $=12.6$, SD $=6.9, p<0.001)$ and daytime sleepiness (avg $=21.7, \mathrm{Sd}$ $=6.6, p=0.001$ ) (Table 3).

The overall mean and SD of sleeping patterns against age of child (0-11 months, 1-2 yrs and 3-4 yrs) is given in the Table 4.

\section{Discussion}

The present study demonstrated that Saudi children were exposed to inadequate bedtime habits in all age groups, with total nocturnal sleep duration below the recommended level.

The National Sleep Foundation (NSF) recommends a daily sleep duration of 14-17 hours/day from birth to 3

Table 3: Sleeping pattern compared with different sleep parameters.

\begin{tabular}{|c|c|c|c|c|c|c|c|c|c|c|c|c|c|}
\hline \multirow[t]{2}{*}{ Characteristics } & \multirow[b]{2}{*}{$N=1264$} & \multicolumn{3}{|c|}{ Bedtime Resistance } & \multicolumn{3}{|c|}{ Sleep Anxiety } & \multicolumn{3}{|c|}{ Night Wakening } & \multicolumn{3}{|c|}{ Daytime Sleepiness } \\
\hline & & Mean & SD & p-value & Mean & SD & p-value & Mean & SD & p-value & Mean & SD & p-value \\
\hline \multicolumn{14}{|l|}{$\begin{array}{l}\text { Job Status of } \\
\text { Mother }\end{array}$} \\
\hline Employed & 501 & 23.7 & 7.7 & 0.122 & 18.3 & 7.4 & $<0.001$ & 12.9 & 5.9 & 0.374 & 21.8 & 6.5 & 0.019 \\
\hline Homemaker & 662 & 22.8 & 7.7 & - & 16.5 & 7.7 & - & 12.7 & 6.2 & - & 20.7 & 6.7 & - \\
\hline Married student & 101 & 22.6 & 7.7 & - & 16.4 & 7.9 & - & 12.0 & 6.9 & - & 20.5 & 6.6 & - \\
\hline Total & 1264 & 23.0 & 7.7 & - & 17.2 & 7.7 & - & 12.5 & 6.3 & - & 21.0 & 6.6 & - \\
\hline \multicolumn{14}{|l|}{ Age of Child } \\
\hline $0-11$ months & 54 & 22.8 & 8.6 & 0.590 & 17.3 & 6.8 & 0.006 & 13.5 & 8.5 & $<0.001$ & 22.1 & 6.3 & 0.001 \\
\hline $1-2$ yrs & 330 & 22.8 & 7.6 & - & 16.1 & 7.8 & - & 10.7 & 6.4 & - & 22.2 & 6.9 & - \\
\hline $2-4$ yrs & 880 & 23.3 & 7.7 & - & 17.7 & 7.6 & - & 13.5 & 5.7 & - & 20.7 & 6.5 & - \\
\hline Total & 1264 & 22.6 & 7.9 & - & 17.0 & 7.4 & - & 12.6 & 6.9 & - & 21.7 & 6.6 & - \\
\hline \multicolumn{14}{|c|}{ Mode of Childbirth } \\
\hline C-section & 332 & 22.9 & 7.6 & 0.635 & 16.7 & 7.7 & 0.153 & 12.6 & 5.8 & 0.621 & 20.5 & 6.8 & 0.045 \\
\hline Vaginal & 932 & 23.2 & 7.8 & - & 17.4 & 7.6 & - & 12.8 & 6.3 & - & 21.4 & 6.5 & - \\
\hline Total & 1264 & 23.0 & 7.7 & - & 17.0 & 7.7 & - & 12.7 & 6.0 & - & 20.9 & 6.7 & - \\
\hline \multicolumn{14}{|l|}{ Type of family } \\
\hline Nuclear & 1039 & 23.1 & 7.7 & 0.827 & 17.2 & 7.7 & 0.513 & 12.5 & 6.1 & 0.010 & 21.2 & 6.5 & 0.324 \\
\hline Extended & 190 & 22.4 & 7.9 & - & 17.7 & 7.4 & - & 13.9 & 6.3 & - & 20.8 & 6.8 & - \\
\hline Joint & 35 & 22.6 & 8.3 & - & 16.1 & 7.2 & - & 13.6 & 6.5 & - & 19.7 & 7.9 & - \\
\hline Total & 1264 & 22.7 & 7.9 & - & 17.0 & 7.4 & - & 13.3 & 6.3 & - & 20.6 & 7.1 & - \\
\hline \multicolumn{14}{|l|}{ Sleep Onset } \\
\hline Within $20 \mathrm{mts}$ & 604 & 22.6 & 7.4 & 0.025 & 16.1 & 7.5 & $<0.001$ & 12.3 & 5.8 & 0.015 & 21.3 & 6.2 & 0.437 \\
\hline$>20 \mathrm{mts}$ & 660 & 23.6 & 7.9 & - & 18.2 & 7.6 & - & 13.1 & 6.5 & - & 20.9 & 7.0 & - \\
\hline Total & 1264 & 23.1 & 7.7 & - & 17.2 & 7.6 & - & 12.7 & 6.2 & - & 21.1 & 6.6 & - \\
\hline \multicolumn{14}{|l|}{ Sleep duration } \\
\hline$<10 \mathrm{hrs}$ & 480 & 23.3 & 7.9 & 0.619 & 18.5 & 7.9 & $<0.001$ & 12.9 & 6.2 & 0.219 & 21.7 & 6.7 & 0.036 \\
\hline $10-12$ hrs & 656 & 22.9 & 7.6 & - & 16.4 & 7.4 & - & 12.5 & 5.9 & - & 20.8 & 6.6 & - \\
\hline $12-14 \mathrm{hrs}$ & 111 & 23.7 & 7.6 & - & 16.7 & 6.5 & - & 13.0 & 6.6 & - & 20.1 & 6.2 & - \\
\hline$>14 \mathrm{hrs}$ & 17 & 23.8 & 6.9 & - & 15.0 & 9.2 & - & 15.0 & 7.7 & - & 22.9 & 6.6 & - \\
\hline Total & 1264 & 23.4 & 7.5 & - & 16.7 & 7.8 & - & 13.4 & 6.6 & - & 21.4 & 6.5 & - \\
\hline
\end{tabular}


Table 4: Sleep parameters vs. child's age.

\begin{tabular}{|l|l|l|l|}
\hline & $\begin{array}{l}\mathbf{0 - 1 1} \text { year } \\
\mathbf{( N = 5 4 )}\end{array}$ & $\begin{array}{l}\mathbf{1 - 2} \text { years } \\
\mathbf{( N = 3 3 0 )}\end{array}$ & $\begin{array}{l}\text { Mean (SD) } \\
\text { years }\end{array}$ \\
\hline & Mean (SD) & $\mathbf{8 8 0 )}$ \\
\hline Bedtime resistance & $22.8(8.56)$ & $22.8(7.65)$ & Mean (SD) \\
\hline Sleep anxiety & $17.3(6.85)$ & $16.1(7.78)$ & $23.3(7.71)$ \\
\hline Night Walking & $13.5(8.50)$ & $10.7(6.39)$ & $17.7(7.59)$ \\
\hline Daytime Sleepiness & $22.1(6.34)$ & $22.2(6.97)$ & $13.5(5.71)$ \\
\hline
\end{tabular}

months, 12-15 hours/day from 4 to 11 months, 11-14 hours/day for infants aged 1-2 years, and 10-13 hours/ day for pre-schoolers aged 3-5 years [12]. In the present study conducted, it was found that $53.7 \%$ of 0 to 11 months children slept less than 10 hours per day. The similar difference of sleep duration from the recommended value were noticed in children who fell in the category of 1-2 years and 2-4 years. Inadequate sleep hygiene can lead to delayed onset of sleep, which in turn can result in a child obtaining insufficient sleep [13]. Irregular sleep schedules can interfere with circadian sleep-wake rhythm among children and contribute to difficulties related to sleep onset latency. Children who slept fewer than 10 hours per night had an increase of $0.22 \mathrm{BMI}$ score units in comparison to children getting more than 10 hours of sleep per night $[14,15]$. Critical to good sleep hygiene is also having an age-appropriate bedtime and wake time, as this can help ensure that a child receives sufficient sleep. Indeed, developmentally inappropriate bedtimes (later than 9:00 pm) for children under 10 years are associated with shorter sleep duration. Research suggests that young children who follow a consistent bedtime routine demonstrate shorter sleep onset latency, decreased wakefulness following sleep onset, and increased sleep consolidation as compared to a control group of children [16]. Nearly $56 \%$ of children participated in the study had a sleep time of later than $10.00 \mathrm{pm}$.

A new study which examined associations between a mother's level of education, prenatal depression, method of delivery and her infant's sleep duration which concluded that infants born to mothers without a university degree slept 23 minutes less than infant born to mothers with a university degree. Further, the researchers found that the method of delivery independently predicted infant sleep duration, with infants delivered by C-section slept approximately one hour less per day than infants born by vaginal delivery [17]. The present study also presents an evidence of the association of mode of childbirth with daytime sleepiness $(p=0.045)$ and employment of mother with sleep anxiety $(p<0.001)$ and daytime sleepiness $(p=0.019)$. Because the family system is a central part of a child's life, child sleep problems can have a significant impact on family functioning, in particular parent sleep and daytime functioning (e.g., mood, stress, and marital satisfaction). Likewise, family functioning (e.g., parent stress, marital conflict) may impact child sleep [18].

The present study showed the prevalence and association between sleeping patterns and different sleep parameters. It was recognized that sleep is important in early childhood, and the potential for sleep to elicit better health outcomes remains a significant consideration for researchers, public health practitioners, and the wider community. Higher maternal education has been linked to higher socioeconomic status and increased parenting skills and knowledge [19]. Furthermore, higher education and socioeconomic status have been linked to higher adoption of bedtime routines and better sleep [20].

\section{Conclusion}

Multiple factors within the home environment are associated with shorter sleep in early childhood. The results obtained in the present study suggest that there is a high prevalence of inadequate sleep habits and mean total nocturnal sleep time below the recommended values. The study also reveals that their exist significant association between sleep duration, sleep onset, mothers occupation, education level and sleep patterns like bedtime resistance, sleep anxiety, nocturnal awakening, daytime sleepiness. Future work would investigate how sleeping patterns contribute to child development in domains such as day-to-day functioning, cognitive development, and emotional and behavioural development.

\section{Funding}

This research did not receive any specific grant from funding agencies in the public, commercial, or not-forprofit sectors.

\section{Conflict of Interest}

The authors report no conflicts of interest.

\section{Acknowledgement}

The authors thank the women who volunteered their time to participate in this study.

\section{References}

1. Alamian A, Wang L, Hall AM, Pitts M, Ikekwere J (2016) Infant sleep problems and childhood overweight: Effects of three definitions of sleep problems. Preventive Medicine Reports 4: 463-468. 
2. Hysing M, Sivertsen B, Garthus-Niegel S, Eberhard-Gran M (2016) Pediatric sleep problems and social-emotional problems. A population-based study. Infant Behavior and Development 42: 111-118.

3. Sivertsen B, Harvey AG, Reichborn-Kjennerud T, Torgersen L, Ystrom E, et al. (2015) Later emotional and behavioral problems associated with sleep problems in toddlers: a longitudinal study. JAMA Pediatrics 169: 575-582.

4. Mindell JA, Leichman ES, DuMond C, Sadeh A (2016) Sleep and social-emotional development in infants and toddlers. Journal of Clinical Child and Adolescent Psychology 46: 236-246.

5. Miller AL, Seifer R, Crossin R, Lebourgeois MK (2015) Toddler's self-regulation strategies in a challenge context are nap-dependent. J Sleep Res 24: 279-287.

6. Cassandra L Pattinson, Simon S Smith, Sally L Staton, Stewart G Trost, Karen J Thorpe (2018) Investigating the association between sleep parameters and the weight status of children: Night sleep duration matters. Sleep Health 4: 147-153.

7. Hale L, Berger LM, LeBourgeois MK, Brooks-Gunn J (2011) A longitudinal study of preschoolers' languagebased bedtime routines, sleep duration, and well-being. $J$ Fam Psychol 25: 423-433.

8. Lam JC, Mahone EM, Mason TBA, Steven M Scharf (2011) The effects of napping on cognitive function in preschoolers. J Dev Behav Pediatr 32: 90-97.

9. Mindell JA, C Lee, A Sadeh (2017) Young child and maternal sleep in the Middle East. Sleep Med 32: 75-82.

10. McDowall PS, Galland BC, Campbell AJ, Elder DE (2017) Parent knowledge of children ss sleep: A systematic review. Sleep Med Rev 31: 39-47.
11. Mona El-Sheikh, Avi Sadeh (2015) I. Sleep and Development: Introduction to the Monograph. Monographs of the Society for Research in Child Development 80: 1-14.

12. National Sleep Foundation (2015) National Sleep Foundation recommends new sleep times.

13. Meltzer LJ, Thomas JH, Williamson AA (2016) Sleep disturbances. In: Levesque RJR, Encylcopedia of adolescence. Springer, New York, 1-12.

14. Hirshkowitz M, Whiton K, Albert SM, Alessi C, Bruni O, et al. (2016) National Sleep Foundation's updated sleep duration recommendations: Final report. Sleep Health 1: 233-243.

15. Paruthi S, Brooks LJ, D'Ambrosio C, Hall AW, Kotagal S, et al. (2016) Recommended amount of sleep for pediatric populations: a consensus statement of the American Academy of Sleep Medicine. J Clin Sleep Med 12: 785-786.

16. Mindell JA, Telofski LS, Wiegand B, Kurtz ES (2009) A nightly bedtime routine: Impact on sleep in young children and maternal mood. Sleep 32: 599-606.

17. (2019) Infant sleep duration associated with motherss level of education and prenatal depression. University of Alberta Faculty of Medicine \& Dentistry.

18. Lisa J Meltzer, Hawley E Montgomery-Downs (2011) Sleep in the Family. Pediatr Clin North Am 58: 765-774.

19. Carr A, Pike A (2012) Maternal scaffolding behavior: Links with parenting style and maternal education. Dev Psychol 48: 543-551.

20. El-Sheikh M, Bagley EJ, Keiley M, Elmore-Staton L, Chen E, et al. (2013) Economic adversity and children's sleep problems: multiple indicators and moderation of effects. Health Psychol 32: 849-859. 